\title{
La implementación de los Principios Rectores ONU sobre empresas y derechos humanos en España
}

The implementation of the Guiding Principles ONU on Business and Human Rights in Spain

\section{Inmaculada Vivas-Tesón}

Profesora titular de Derecho civil. Universidad de Sevilla, España.

Resumen: En los últimos años se ha cristalizado la expectativa social de que los entes empresariales, y en particular, las empresas transnacionales, tienen el deber de respetar los derechos humanos. Esta expectativa se ha plasmado, entre otros, en la adopción en 2011 de los Principios Rectores sobre empresas y derechos humanos por el Consejo de Derechos Humanos de Naciones Unidas. En esta comunicación trataremos las implicaciones para España del marco de Naciones Unidas sobre empresas y derechos humanos y sus implicaciones para España.

Palabras clave: derechos humanos; derecho a la salud, violación; empresas transnacionales, responsabilidad civil.

Key-words: human rights; right to health, violation; transnational corporations, liability.

\section{Nota preliminar}

El reciente fenómeno de la globalización de los mercados ha provocado que, en la escena mundial, aparezcan nuevos sujetos que desempeñan un rol de relevancia indiscutible: las empresas transnacionales.

En este sentido, los Principios Rectores sobre empresas y derechos humanos: puesta en práctica del marco de las Naciones Unidas para "proteger, respetar y remediar" (2011) ${ }^{1}$, de aplicación a todos los Estados y a todas las empresas (no sólo a las transnacionales), reconocen el "b) papel de las empresas como órganos

\footnotetext{
${ }^{1}$ Los Principios Rectores sobre empresas y derechos humanos: puesta en práctica del marco de las Naciones Unidas para "proteger, respetar y remediar" fueron elaborados por el Representante Especial del Secretario General para la cuestión de los derechos humanos y las empresas transnacionales y otras empresas. El Representante Especial, el Prof. John Ruggie, adjuntó los Principios Rectores a su informe final al Consejo de Derechos Humanos (A/HRC/17/31) (Naciones Unidas, 2008). El Consejo de Derechos Humanos hizo suyos los Principios Rectores en su Resolución 17/4, de 16 de junio de 2011 (Naciones Unidas, 2011).
} 
especializados de la sociedad que desempeñan funciones especializadas y que deben cumplir todas las leyes aplicables y respetar los derechos humanos".

La presente comunicación gira en torno al inciso final: el deber de cumplir todas las leyes aplicables y respetar los derechos humanos.

No son pocas, lamentablemente, las ocasiones en las cuales las empresas, movidas por una política encaminada estratégicamente a la obtención del máximo beneficio económico y a la expansión comercial, vulneran los derechos humanos, económicos, políticos, sociales y culturales (entre ellos, el derecho a la salud) de los ciudadanos de los países en los que aquéllas desarrollan su actividad productiva, cometiendo, a través de sus sucursales o filiales, graves e intolerables prácticas abusivas que no pueden, bajo ningún concepto, quedar impunes. En definitiva, se trata de ganar dinero a cualquier precio, aun por encima de pisotear la valiosa dignidad humana de las personas.

El mundo se ha convertido en un inmenso escenario donde se cometen sistemáticamente violaciones, directas o indirectas, de derechos humanos por parte tanto de los Estados como de las empresas privadas.

Con enorme frecuencia, la permisividad de tales conductas abusivas por parte de las multinacionales procede de las autoridades públicas responsables, bien las de los países de origen de las empresas multinacionales, bien de las de aquéllos en los cuales las víctimas sufren las violaciones, que miran hacia otro lado a cambio, indudablemente, de beneficios y privilegios de diversa índole, a los que se suma la importancia de no arriesgar las relaciones de política exterior. Ello les confiere a estos agentes económicos un fuerte poder económico, político y jurídico, que los hace, prácticamente, inmunes.

Sin embargo, los Principios Rectores ONU, los cuales establecen un estándar global que especifica los roles respectivos de empresas y gobiernos con el fin de contribuir al respeto de los derechos humanos, se basan en el reconocimiento de: "a) Las actuales obligaciones de los Estados de respetar, proteger y cumplir los derechos humanos y las libertades fundamentales". Por consiguiente, los Estados, tanto donde operan territorialmente las trasnacionales como los de origen de las mismas, no sólo deben "respetar" sino también "proteger", esto es, impedir que terceros (en este caso, las empresas) violen los derechos humanos, así como investigar y punir cuando éstos sean vulnerados. Los Estados tienen la obligación legal de respetar y hacer respetar 
las normas internacionales en materia de derechos humanos. Basta recordar, al respecto, sus obligaciones legales en virtud de lo dispuesto por el art. 11 relativo al derecho a un nivel de vida adecuado, incluyendo una alimentación, vestido y vivienda adecuados $^{2}$ y por el art. 12 al derecho a la salud ${ }^{3}$, ambos del Pacto Internacional de Derechos Económicos, Sociales y Culturales (adoptado y abierto a la firma, ratificación y adhesión por la Asamblea General en su Resolución 2200 A XXI-, de 16 de diciembre de 1966, con entrada en vigor el 3 de enero de 1976). Además de todo ello, deben velar por el debido cumplimiento de sus legislaciones nacionales.

Por su parte, las empresas transnacionales "b)... deben cumplir todas las leyes aplicables y respetar los derechos humanos", establecen los Principios Rectores ONU.

En cuanto a las empresas existe un amplio conjunto de Documentos y Declaraciones de derechos elaborados en el seno de la ONU, si bien quisiéramos destacar las Normas sobre las responsabilidades de las empresas transnacionales y otras empresas comerciales en la esfera de los derechos humanos, adoptadas de forma unánime por la Subcomisión de la ONU para la Promoción y Protección de los Derechos Humanos en el año 2003. Según estas Normas, las empresas deben proporcionar "un entorno laboral seguro y saludable, de conformidad con lo dispuesto

\footnotetext{
${ }^{2}$ Art. 11: "1. Los Estados Partes en el presente Pacto reconocen el derecho de toda persona a un nivel de vida adecuado para sí y su familia, incluso alimentación, vestido y vivienda adecuados, y a una mejora continua de las condiciones de existencia. Los Estados Partes tomarán medidas apropiadas para asegurar la efectividad de este derecho, reconociendo a este efecto la importancia esencial de la cooperación internacional fundada en el libre consentimiento.

2. Los Estados Partes en el presente Pacto, reconociendo el derecho fundamental de toda persona a estar protegida contra el hambre, adoptarán, individualmente y mediante la cooperación internacional, las medidas, incluidos los programas concretos, que se necesitan para:

a) Mejorar los métodos de producción, conservación y distribución de alimentos mediante la plena utilización de los conocimientos técnicos y científicos, la divulgación de principios sobre nutrición y el perfeccionamiento o la reforma de los regímenes agrarios de modo que se logren la explotación y la utilización más eficaces de las riquezas naturales;

b) Asegurar una distribución equitativa de los alimentos mundiales en relación con las necesidades, teniendo en cuenta los problemas que se plantean tanto a los países que importan productos alimenticios como a los que los exportan". (Naciones Unidas, 1966).

${ }^{3}$ Art. 12.: "1. Los Estados Partes en el presente Pacto reconocen el derecho de toda persona al disfrute del más alto nivel posible de salud física y mental.

2. Entre las medidas que deberán adoptar los Estados Partes en el Pacto a fin de asegurar la plena efectividad de este derecho, figurarán las necesarias para:

a) La reducción de la mortinatalidad y de la mortalidad infantil, y el sano desarrollo de los niños;

b) El mejoramiento en todos sus aspectos de la higiene del trabajo y del medio ambiente;

c) La prevención y el tratamiento de las enfermedades epidémicas, endémicas, profesionales y de otra índole, y la lucha contra ellas;

d) La creación de condiciones que aseguren a todos asistencia médica y servicios médicos en caso de enfermedad". (Naciones Unidas, 1966).
} 
en los instrumentos internacionales y la legislación nacional pertinentes, así como en las normas internacionales de derechos humanos $y$ en el derecho internacional humanitario" (Letra D.7). Además, "las empresas transnacionales y otras empresas comerciales respetarán los derechos económicos, sociales y culturales, así como los derechos civiles y políticos, y contribuirán a que se ejerzan, en particular los derechos al desarrollo, a una alimentación, una salud y una vivienda adecuadas, a la educación, a la libertad de pensamiento, conciencia y religión y a la libertad de opinión y expresión, y se abstendrán de todo acto que impida el ejercicio de esos derechos"(E.12).

Sin embargo, las vulneraciones de los derechos más fundamentales, como el de la salud o la vida, de las poblaciones más vulnerables (en ocasiones, su vulnerabilidad es doble o triple, si se trata de mujeres, niños o personas con discapacidad) no son infrecuentes (ej. contaminación ambiental, trabajar en condiciones muy adversas en cuanto a higiene y seguridad - manipulación de productos tóxicos -, sobreexplotación, imposición de trabajo forzado e infantil etc.), contribuyendo a la degradación de sus condiciones de vida que les conducen al padecimiento de enfermedades y a una muerte prematura.

Cierto es que algunas empresas, conscientes de su responsabilidad en esta materia, han asumido el compromiso de incorporar normas y principios éticos y de derechos humanos en sus actuaciones: la llamada "responsabilidad social corporativa" (RSE). Sin embargo, con estas buenas prácticas en RSC las empresas pretenden ofrecer una imagen de respeto a los derechos humanos en su actividad productiva cuando, en realidad, están enmascarando violaciones de todo tipo. Además, carecen de coercibilidad jurídica.

La complicidad o connivencia de los Estados unida al carácter transnacional de estas empresas les permite escapar a las leyes y reglamentaciones nacionales e internacionales que consideran desfavorables a sus intereses, hace surgir la urgente necesidad de crear un adecuado marco jurídico aplicable a las actividades de las empresas internacionales basado en tres pilares esenciales: proteger, respetar y remediar.

Tras el lanzamiento, en octubre de 2011, por parte de la Comisión Europea (UE) de la Estrategia renovada de la UE para 2011-2014 sobre la Responsabilidad Social de las Empresas, que anima a los Estados miembros a desarrollar un Plan 
Nacional para la implementación del Marco de John Ruggie, España, a través de la Oficina de Derechos Humanos (ODH) del Ministerio de Asuntos Exteriores y Cooperación, ha puesto en marcha la elaboración de un Plan Nacional sobre Empresas y Derechos Humanos.

Es por ello por lo que creemos imprescindible realizar un breve diagnóstico de los actuales mecanismos del Ordenamiento jurídico español, a fin de identificar los elementos acordes con los Principios Rectores y las carencias respecto de los mismos.

A la espera de que dicho Plan vea la luz, apuntaremos, sucintamente, algunos aspectos de la problemática jurídica que rodea a las violaciones graves de derechos humanos por parte de las empresas transnacionales. Se trata de cuestiones pertenecientes a distintos sectores del Ordenamiento jurídico, pero, en la práctica, se presentan enrevesadamente entrelazadas, lo que complica, en ocasiones, su estudio, razón por la cual intentaremos analizarlas de manera separada.

\section{Cuestiones de Derecho internacional privado}

El art. 8.1 del Código Civil Español -en adelante, C.c.- (Álvarez González, 2010, Comentarios del Código civil) dispone que las leyes penales obligan a todos los que se hallen en territorio español, proclamándose, así, el llamado principio de territorialidad del Derecho público sancionatorio.

Si lo anterior es claro, la dificultad que se encuentra en este ámbito podría formularse del siguiente modo: el Estado bajo cuya legislación se ha constituido una empresa privada ${ }^{4}$ (supongamos, España) que despliega su actividad en un país distinto en el cual comete una violación de derechos humanos ¿puede ejercer sobre dicha persona jurídica lo que se llama la "jurisdicción extraterritorial"?

Siguiendo a Zambrana Tévar (2013, "La Jurisdicción extraterritorial y violaciones de los derechos humanos por empresas transnacionales"), puede afirmarse que existen tres tipos de jurisdicción extraterritorial:

1. el poder de un Estado para adoptar normas que regulen personas, propiedad o conductas que tienen lugar en el territorio de otro Estado (jurisdicción normativa);

\footnotetext{
${ }^{4}$ Si la empresa que actúa extraterritorialmente es pública o semipública entendemos que actúa bajo la dirección del Estado y, por consiguiente, éste es responsable.
} 
2. el poder de los tribunales de un Estado para tomar decisiones relativas a situaciones que se han originado en otro Estado (jurisdicción judicial); y

3. el poder de un Estado para desplegar las actividades de sus órganos en el territorio de otro Estado (jurisdicción ejecutiva).

Con excepción del supuesto de los crímenes internacionales (genocidio, guerra etc.), no existe una obligación general, impuesta a los Estados, conforme al Derecho internacional de los derechos humanos, de ejercer su jurisdicción extraterritorial, con el fin de contribuir a la protección y promoción de los derechos humanos internacionalmente reconocidos.

Además, ante violaciones de derechos humanos, el ejercicio de la jurisdicción extraterritorial sobre la base del principio de nacionalidad de la empresa por parte del Estado de origen necesitaría la cooperación internacional del Estado donde la empresa opera, razón por la cual nos topamos con uno de los obstáculos frecuentes en esta materia, la connivencia del Estado con las empresas que desarrollan en sus territorios su actividad productiva.

Otro dato a tener en cuenta es que no todos los países contemplan la responsabilidad penal de las personas jurídicas y, si la contemplan, no lo hace de la misma manera.

Por otra parte, si el Estado origen regulara las actividades de dichas empresas en el extranjero, es posible que dicha regulación despertara cierta antipatía por parte del Estado donde la empresa opera, bien por no compartirla en cuanto a su contenido, bien por considerar que aquélla limita su capacidad de actuación y en cuyo caso la percibiría como una intromisión o amenaza a la soberanía del Estado donde operan las empresas, bien por interpretar que el Estado de origen duda acerca de su habilidad para afrontar por sí solo y eficazmente el problema.

\section{Cuestiones de Derecho societario}

La cuestión del ejercicio de la jurisdicción extraterritorial está íntimamente relacionada con la nacionalidad de la persona jurídica, la cual determina la ley aplicable ex art. 9.11 C.c (Álvarez Gonzáles, 2010, p. 83) ${ }^{5}$.

\footnotetext{
${ }^{5}$ Para Álvarez González (2010, sub art. 9.11, p. 83), precepto al que califica de "cuerpo extraño", "la noción de «nacionalidad» de las personas jurídicas muestra una gran diversidad en Derecho comparado; diversidad que puede dar lugar a situaciones «paralelas» a la de la plurinacionalidad de
} 
Para la determinación de la nacionalidad española y, por consiguiente, saber cuándo la ley española es la lex societatis, se utilizan distintos criterios legales (Requejo Isidro, 2012, p. 125) ${ }^{6}$ :

$\checkmark \quad$ A las sociedades civiles y las mercantiles personalistas se les aplica el art. 28 C.c. y el art. 15 del Código de Comercio, respectivamente, que señalan que son españolas las sociedades constituidas y domiciliadas en España.

$\checkmark \quad$ A las sociedades mercantiles de capital les resulta de aplicación lo dispuesto por el art. 8 del Real Decreto Legislativo 1/2010, de 2 de julio, por el que se aprueba el texto refundido de la Ley de Sociedades de Capital, el cual establece que son españolas las sociedades domiciliadas en España con independencia del lugar de constitución.

Al respecto, ha de señalarse que se echa en falta una norma que fije cuál es la nacionalidad de la sociedad no española.

Pues bien, los problemas comienzan cuando la empresa transnacional se ramifica a través de sucursales (en cuyo caso, no adquieren personalidad jurídica propia, teniéndola la sociedad matriz) y filiales (sí adquieren personalidad jurídica propia e independiente de la matriz), busca socios contractuales en otros países, o bien se fusiona con otras sociedades de diversa nacionalidad, en cuyo caso se trata de sociedades que actúan en distintas naciones y cuyo capital pertenece a personas domiciliadas en diferentes países, burlando el control jurídico.

El problema se centra, entonces, en la atribución o imputación de responsabilidad, salvo en el caso de las sucursales, pues los actos de éstas se atribuyen a la matriz. La complejidad del entramado societario, consciente y

las personas físicas; situaciones para las que se ha propuesto una aplicación, sin duda no en sus estrictos términos, del analizado art. 9.9 y 10 C.c.". Y añade: "ha de tenerse en cuenta, junto al particularismo del Derecho comparado, el hecho de que gran parte de los problemas que suscitan hoy en día las personas jurídicas en su actividad transnacional se enfocan en términos de reconocimiento de dichas personas jurídicas y no en términos de ley aplicable".

${ }^{6}$ Señala Requejo Isidro (2010, sub art. 28, p. 125) que en el ámbito del Derecho comparado existe una gran variedad de criterios para determinar la nacionalidad de la persona jurídica, que dan lugar a distintas teorías: la de la incorporación/constitución de la sociedad, según la cual la lex societatis es la ley del Estado conforme a cuyo Derecho se haya constituido la sociedad; la de sede real, que determina que es lex societatis la del Estado en cuyo territorio tiene sede real la sociedad; modelos mixtos, donde se someten unos aspectos de la sociedad al Derecho del Estado donde tiene sede real, mientras otros quedan sometidos al Ordenamiento del Estado de incorporación/constitución. Como señala la autora, "consecuencia de la divergencia en los criterios entre los distintos Ordenamientos son los casos de apatridia de la persona jurídica que no reúna los criterios exigidos por ningún Ordenamiento jurídico de aquellos con los que presenta conexión; o de doble o múltiple nacionalidad, si concurren las exigencias impuestas por más de un Ordenamiento para conceder la nacionalidad". 
voluntariamente buscada con fines fraudulentos nos conduce a la doctrina jurisprudencial del "levantamiento del velo" de la personalidad jurídica ${ }^{7}$ para poder descubrir a quién (la filial, la matriz, los socios contractuales etc.) puede imputarse directamente la responsabilidad.

\section{Cuestiones de Derecho civil}

Otro tema importante es el relativo al remedio civil, consistente en la reparación pecuniaria del daño producido a la víctima.

Nos situamos ante la responsabilidad civil extracontractual o aquiliana y preciso es recordar que ésta pueda derivar o no de delito, atribuible éste, según los distintos Ordenamientos jurídicos, bien a la persona jurídica, bien individualmente a sus dirigentes.

Según el art. 1902 C.c., "el que por acción u omisión causa daño a otro, interviniendo culpa o negligencia, está obligado a reparar el daño causado". Coloquialmente, "el que la hace la paga". Por su parte, el art. 1903 C.c. se ocupa de la responsabilidad del empresario por hecho ajeno, al establecer que son responsables "los dueños o directores de un establecimiento o empresa respecto de los perjuicios causados por sus dependientes en el servicio de los ramos en que los tuvieran empleados, o con ocasión de sus funciones".

La responsabilidad civil por violación de derechos humanos podría corresponder tanto a los Estados (tanto de origen como los que permiten que

\footnotetext{
7 Según nuestro Tribunal Supremo, en su Sentencia núm. 482/2003, de 19 de mayo de 2003, que recoge su anterior pronunciamiento de 15 de octubre de 1997, "la doctrina del llamado levantamiento del velo de la persona jurídica, expresión que es adaptación de la anglosajona disregard y de la germana Durchgriff, que tiene como función evitar el abuso de una pura fórmula jurídica y desvela las verdaderas situaciones en orden a la personalidad, para evitar ficciones fraudulentas, tal como dice la Sentencia de 28 de mayo de 1984, verdaderamente emblemática en esta cuestión y que ha sido seguida, incluso a veces con literalidad, por las Sentencias de 16 de julio de 1987, 24 de septiembre de 1987, 5 de octubre de 1988, 20 de junio de 1991, 12 de noviembre de 1991, 12 de febrero de 1993. La idea básica es que no cabe la alegación de la separación de patrimonios de la persona jurídica por razón de tener personalidad jurídica, cuando tal separación es, en la realidad, una ficción que pretende obtener un fin fraudulento, como incumplir un contrato, eludir la responsabilidad contractual o extracontractual, aparentar insolvencia, etc. Tal como dice la Sentencia de 3 de junio de 1991 se proscribe la prevalencia de la personalidad jurídica que se ha creado si con ello se comete un fraude de ley o se perjudican derechos de terceros; lo que reiteran las de 16 de marzo de 1992, 24 de abril de 1992, 16 de febrero de 1994, y la de 8 de abril de 1996"; sentencias posteriores reiteran la doctrina: 23 de enero de 1998, 25 de mayo de 1998, 11 de octubre de 1999, 31 de enero de 2000, 11 de octubre de 2000, 22 de noviembre de 2000..." (FJ. $2^{\circ}$ ). (Base de datos Westlaw, Editorial Aranzadi, RJ 200315213).
} 
desarrollen sus actividades en su territorio) o a las empresas transnacionales, por infracción de su deber de respetar los derechos humanos y, además, aquellos, como garantes de los mismos.

Vaya por delante que somos plenamente conscientes de que, difícilmente una indemnización logra reparar, siquiera mínimamente, un derecho humano que resulte vulnerado, piénsese en el derecho a la salud, pero, en nuestra modesta opinión, el posible ejercicio de una acción civil y la consiguiente condena pecuniaria es un buen remedio disuasorio para que las empresas transnacionales tomen conciencia de su deber de respetar los derechos humanos y libertades fundamentales, pues, al fin y al cabo y para entendernos, lo que les duele es el bolsillo.

Se trata, sin duda, de un mecanismo jurídico más, de importancia secundaria respecto a otros, pero cuya existencia y puesta en práctica tal vez favorezca que las empresas, ante el temor de ser demandadas (y condenadas) por la vía de la jurisdicción civil, sean más sensibles y respetuosas con los derechos humanos y con la dignidad de la persona ${ }^{8} \mathrm{e}$, incluso, ya producida la violación, busquen una negociación a fin de ocultar la conducta nociva para evitar, a toda costa, dar una mala imagen pública que pueda perjudicar su actividad empresarial.

Son muchas las cuestiones problemáticas que plantea la exigencia de responsabilidad extracontractual a las empresas transnacionales por parte de los particulares, que se suman a las que ya han ido mencionándose (p. ej. las dificultades para identificar al responsable del daño dentro del complejo societario).

El remedio civil tiene la ventaja de ser un instrumento tuitivo cercano a la víctima, es decir, que no requiere agotar vías previas para llegar a él.

Si bien la acción civil tiene la ventaja de iniciarse a instancia de parte, por tanto, singularmente sin depender ni de los correspondientes gobiernos ${ }^{9}$ ni de figuras institucionales a quienes compete la acusación (como el Ministerio Fiscal) en el orden penal (REQUEJO ISIDRO, 2009), tenemos que ser conscientes de las barreras de

\footnotetext{
${ }^{8}$ En este sentido, "partiendo de que en realidad nada puede compensar las pérdidas ni las lesiones físicas o psíquicas de las víctimas de violaciones de derechos humanos fundamentales, la doctrina predica la bondad de la vía civil frente al (relativo) desamparo en que el Derecho Internacional deja a los particulares frente a los desmanes del poder estatal; también, frente a los particulares a la escasa voluntad de los Estados de llevar a cabo una persecución penal de representantes de otros países" (Requejo Isidro, 2009, p. 41).

"El recurso a la vía civil interesa porque tiene menos implicaciones políticas, al no requerir el apoyo del gobierno de la nacionalidad del demandante" (Requejo Isidro, 2009, p. 41).
} 
índole práctica que, en ciertas ocasiones, pueden encontrarse algunas víctimas para acceder a la justicia a fin de exigir la reparación de los derechos que le han sido vulnerados.

Tal vez sería conveniente regular, en este ámbito, una acción civil colectiva cuando el número de damnificados es elevado.

En relación al daño por vulneración de un derecho humano, existe, sin duda, un importante problema en torno a la prueba y a la valoración de aquél.

Descendiendo al concreto aspecto normativo, pensando en el Plan Nacional que está actualmente gestándose y en nuestra modesta propuesta al respecto, ante la falta de una ley como la americana Alien Tort Statute de 1789 y contando exclusivamente con leyes extracodiciales de responsabilidad civil objetiva o por riesgo (p. ej. daños causados por productos defectuosos, por vehículos a motor, en la navegación aérea o por la energía nuclear), no creemos que la redacción del art. 1902 C.c. deba tocarse ni un ápice. Su perfecto tenor literal ha sobrevivido a conductas dañosas de todo tipo y absolutamente inimaginables por el legislador cuando redactó el precepto. Ésta es una más que tiene perfecta cabida en su letra, añeja y actual al mismo tiempo.

Por último, en materia de responsabilidad civil por violaciones a derechos humanos, es absolutamente indispensable lograr que las distintas regulaciones nacionales afronten la cuestión de manera homogénea y uniforme.

En definitiva, si prosperará o no el remedio reparador civil, tan sólo podemos decir que son nuestros Tribunales civiles los que tienen la última palabra.

\section{Referencias}

ÁLVAREZ GONZÁLEZ, S. Comentarios al Código civil. En: DOMíNGUEZ LUELMO, Andrés (Dir.). Madrid: Lex Nova, 2010.

NACIONES UNIDAS. Consejo de Derechos Humanos. Informe final del Representante Especial del Secretario General para la Cuestión de los Derechos Humanos y las Empresas Transnacionales y otras Empresas (A/HRC/17/31), 2011. Disponible em: http://www.ohchr.org/Documents/Publications/GuidingPrinciplesBusinessHR SP.pdf (fecha de consulta: 13/08/2013).

NACIONES UNIDAS. Consejo de Derechos Humanos. Resolución 17/4, de 16 de junio de 2011 (A/HRC/RES/17/4). Disponible em: http://www.businesshumanrights.org/media/documents/resolucion-consejo-derechos-humanos-empresasderechos-humanos-6-julio-2011.pdf (fecha de consulta: 13/08/2013). 
REQUEJO ISIDRO, Marta. Comentarios al Código civil. En: DOMÍNGUEZ LUELMO, Andrés (Dir.). Madrid: Lex Nova, 2010.

REQUEJO ISIDRO, Marta. Violaciones graves de derechos humanos $y$ responsabilidad civil. Cizur Menor (Navarra): Thomson-Aranzadi, 2009.

ZAMBRANA TÉVAR, Nicolás. "2013, "La Jurisdicción extraterritorial y violaciones de los derechos humanos por empresas transnacionales". Disponible em: http://aquiescencia.net/category/derechos-humanos (fecha de consulta: 13/08/2013). 